\title{
Changes of Treg and Th17 cells as well as cytokines in children with acute bronchitis
}

\author{
ZHIQIANG TU, HAIYAN XUE, WEI CHEN, LANFANG CAO and WEIQI ZHANG
}

Department of Pediatrics, Renji Hospital, School of Medicine, Shanghai Jiaotong University, Shanghai 200001, P.R. China

Received October 14, 2016; Accepted June 6, 2017

DOI: $10.3892 /$ etm.2017.4992

\begin{abstract}
The present study aimed to investigate changes of T-regulatory (Treg) and T-helper (Th)17 cells as well as cytokines in peripheral blood of children with acute bronchitis, and to explore the roles of these cells in the pathogenesis of acute bronchitis. A total of 126 children who had presented at Renji Hospital (Shanghai, China) with acute bronchitis were selected as the observation group and 30 healthy children were selected as the control group. Th17/Tregs in the peripheral blood of the children of the observation group and the control group was detected by flow cytometry. The levels of cytokines interleukin (IL)-17, IL-22, IL-10 and transforming growth factor (TGF)- $\beta$ in peripheral blood serum were detected by ELISA. Compared with those in the control group, Treg cells, the Treg/Th17 ratio as well as serum IL-10 and TGF- $\beta$ levels were significantly decreased in the observation group $(\mathrm{P}<0.05)$, while Th17 cells as well as serum levels of IL-17 and IL-22 were significantly increased $(\mathrm{P}<0.05)$. In conclusion, Treg/Th17 and the expression of associated cytokines lost their balance in children with acute bronchitis, suggesting that Treg and Th17 cells as well as their cytokines may be involved in the pathogenesis of acute bronchitis. It may be of certain guiding significance to detect Treg/Th17 and levels of serum cytokines in peripheral blood for clinical treatment.
\end{abstract}

\section{Introduction}

Acute bronchitis is a common respiratory disease in children. It often occurs secondary to upper respiratory tract infection. The symptoms include cough and expectoration caused by inflammation of the bronchial mucosa. The disease commonly occurs in infants and its morbidity is higher in the winter and spring $(1,2)$. Modern medical research has demonstrated that

Correspondence to: Dr Weiqi Zhang, Department of Pediatrics, Renji Hospital, School of Medicine, Shanghai Jiaotong University, 145 Shandong Zhong Road, Shanghai 200001, P.R. China

E-mail: weiqizhangen@163.com

Key words: acute bronchitis, Treg cell, Th17 cell, cytokine the disease is mainly caused by viruses, bacteria or mixed infection (3). Mycoplasma pneumoniae infection is also a common cause. Administration of anti-infective agents is the main treatment method for acute bronchitis (4-6). Long-term treatment with large doses of antibiotics results in an increase of bacterial resistance and dysbacteriosis as well as an enhancement of toxic side effects. Therefore, study on the pathogenesis of acute bronchitis may assist in developing targeted treatments. A large number of clinical studies revealed that respiratory tract infection is an important factor to cause acute bronchitis $(7,8)$. Infection may induce a variety of cytokines being directly or indirectly involved in the inflammatory reaction, so as to promote the exudation and chemotaxis of inflammatory cells, activation and pyrogenicity of inflammatory cells, and participate in inflammatory pathological damage. Therefore, immunological mechanisms have an important role in acute bronchitis $(9,10)$. Previous studies identified immune dysfunction in patients with acute bronchitis, in which a dysfunction in the type $1 \mathrm{~T}$-helper cell (Th1)/Th2 subpopulation was mostly studied in the pathogenesis of acute bronchitis. After T-regulatory (Treg) and Th17 cells were successively identified, the imbalance of Treg/Th17 and cytokines has become a theoretical basis for the study of immune disorders and other diseases $(11,12)$. In the present study, the expression of Treg/Th17 and cytokines in peripheral blood were detected in children with acute bronchitis, in order to further investigate the role of Treg/Th17 in the pathogenesis of acute bronchitis and its clinical significance.

\section{Subjects and methods}

General data. A total of 126 children who presented with acute bronchitis at Renji Hospital (Shanghai, China) were selected as the observation group from February 2014 to October 2015. The patients were diagnosed according to the diagnostic criteria for acute bronchitis in 'practical pediatrics' (13). All children had clinical manifestations including fever, cough, expectoration and lung rales. The patients were seen by the doctors within 2 days of the onset of acute bronchitis. None of the patients were treated with any antibacterial drugs prior to or after the attack. Severe cases or those complicated with other infections diseases were excluded from the present study. A total of 75 male and 51 female patients with acute bronchitis [age, 5.6 \pm 2.9 years 
(range, 2.2-7.5 years); body weight, 20.5 $\pm 8.7 \mathrm{~kg}$ ] were enrolled in the observation group. Furthermore, 30 healthy children undergoing physical examination at Renji Hospital (Shanghai, China) during the same period were enrolled as the control group, including 17 males and 13 females [age, 6.1 \pm 3.1 years (range, $2.3-8.5$ years); body weight, $21.7 \pm 8.8 \mathrm{~kg}$ ]. There were no significant differences in age, sex, weight or any other aspects between the two groups $(\mathrm{P}>0.05)$. The present study was performed in accordance with the declaration of Helsinki and approved by the Ethics Committee of Renji Hospital (Shanghai, China). Written informed consent was obtained from the parents/guardians of all participants.

Specimen collection. Blood was collected in tubes containing heparin anticoagulant $(2 \mathrm{ml})$ was asepticly collected from all patients after hospitalization for 1 day. Treg and Th17 cell contents were detected. A total of $2 \mathrm{ml}$ peripheral blood was collected in non-anticoagulant tubes, coagulated at room temperature for $30 \mathrm{~min}$ and centrifuged at $1,400 \mathrm{x} \mathrm{g}$ at room temperature for $5 \mathrm{~min}$. The serum was immediately collected and stored at $-80^{\circ} \mathrm{C}$ for detection of interleukin (IL)-17, IL-22, IL-10 and transforming growth factor (TGF)- $\beta$. The blood collection method for all healthy control subjects was similar to the above.

Detection of Treg cells in peripheral blood. Treg cells were determined from $100 \mu 1$ whole blood collected in anticoagulant tubes. A total of $10 \mu \mathrm{l} \mathrm{CD} 4$-fluorescein isothiocyanate (FITC) monoclonal antibody (mAb) (cat. no. 11-0040-81; eBioscience, San Diego, CA, USA) and $10 \mu \mathrm{l}$ CD25-peridinin-chlorophyll-protein complex (cat. no. 45-0251; eBioscience) were added, followed by mixing, incubation in the dark for $15 \mathrm{~min}$ and washing with PBS. Fix/Perm liquid (Sigma-Aldrich; Merck KGaA, Darmstadt, Germany) was added to fix/penetrate the membrane while standing at $4^{\circ} \mathrm{C}$ for $30 \mathrm{~min}$, followed by centrifugation at $1,200 \mathrm{x} \mathrm{g}$ at $4^{\circ} \mathrm{C}$ for $3 \mathrm{~min}$. The supernatant was discarded and the sample was washed using Fix/Perm buffer, followed by centrifugation at $1,200 \mathrm{x}$ at $4^{\circ} \mathrm{C}$ for $3 \mathrm{~min}$. The supernatant was removed and $10 \mu \mathrm{l}$ phycoerythrin (PE)-labeled anti-human forkhead box P3 (Foxp3) antibody (cat. no. 72-5776-40; eBioscience) was added to the tube. The control antibody (eBioscience) was added in the same control tube, mixed and incubated at room temperature away from light for $20 \mathrm{~min}$; The sample was washed using Fix/Prem buffer; centrifuged at $1,200 \mathrm{x} \mathrm{g}$ at room temperature for $3 \mathrm{~min}$. The supernatant was discarded, and the cells were re-suspended in $500 \mu \mathrm{l}$ PBS and detected using the flow cytometry (FACSCalibur; BD Biosciences). The CD25+ cells were differentiated. Subsequently, the CD4 ${ }^{+}$Foxp $3^{+}$cells were measured. A scatter diagram was used to determine the Treg cell ratio.

Th17 cell ratio in peripheral blood. Th17 cells were determined from whole blood collected in anticoagulant tubes. First, peripheral blood mononuclear cells were isolated using human lymphocyte separating medium (Dingguo, Beijing, China). The cell density was adjusted to $2 \times 10^{6} / \mathrm{ml}$ using RPMI-1640 culture medium (Thermo Fisher Scientific, Inc.,
Waltham, MA, USA). The suspension was added to a 6-well plate at $2 \mathrm{ml} /$ well, followed by addition of $50 \mathrm{ng} / \mathrm{ml}$ phorbol ester and $1 \mu \mathrm{g} / \mathrm{ml}$ ionomycin (both from Invitrogen; Thermo Fisher Scientific, Inc.). The sample was cultured at $37^{\circ} \mathrm{C}$ in an incubator with $5 \% \mathrm{CO}_{2}$ for $1 \mathrm{~h}$. A total of $1.5 \mu \mathrm{g} / \mathrm{ml}$ monensin (Invitrogen; Thermo Fisher Scientific, Inc.) was added, followed by culture at $37^{\circ} \mathrm{C}$ for $6 \mathrm{~h}$. The cells were transferred to a homotype control tube and detector tube, to which $10 \mu \mathrm{l}$ CD4-FITC mAb (eBioscience) was added, followed by mixing at room temperature and incubation away from light for $15 \mathrm{~min}$ and washing with PBS. The cells were fixed with $4 \%$ paraformaldehyde and left to stand at room temperature for $20 \mathrm{~min}$. Permeabilization wash buffer (Bioco Laibo Technology Co., Ltd., Beijing, China) was added, the sample was placed at room temperature for $10 \mathrm{~min}$ and then centrifuged at $1,200 \mathrm{x} \mathrm{g}$ at room temperature for $10 \mathrm{~min}$. The supernatant was removed, the cells were re-suspended in PBS and $10 \mu \mathrm{l}$ anti-human PE-IL-17 mAb (cat. no. 12-7178-41; eBioscience) was added to the detector tube. Furthermore, $10 \mu 1$ homotype control antibody PE-immunoglobulin G1 mAb (cat. no. 12-0259-41; eBioscience) was added to the isotype control tube, followed by incubation at room temperature away from light for $30 \mathrm{~min}$ and washing with PBS. The cells were then detected by flow cytometry. The ratio of $\mathrm{CD}^{+}, \mathrm{IL}-17^{+}$cells accounting for $\mathrm{CD}^{+} \mathrm{T}$ cells was the Th17-cell ratio.

Detection of serum cytokine levels. The frozen serum was removed. The levels of IL-10, IL-22, IL-17 and TGF- $\beta$ were detected strictly in accordance with the instructions of the ELISA kits (kits for IL-10 and IL-22 were from Jiancheng, Nanjing, China; IL-17 and TGF- $\beta$ kits were from Roche, Basel, Switzerland). For each sample and standard substance, 3 complex holes were set. The optical density (OD) value was measured at $492 \mathrm{~nm}$ using a microplate reader (Thermo Fisher Scientific, Inc.).

Statistical analysis. All data were analyzed using the SPSS 13.0 statistical software (SPSS Inc., Chicago, IL, USA). Values are expressed as the mean \pm standard deviation and compared using the Student's t-test. Enumeration data were compared using the chi square test. $\mathrm{P}<0.05$ was considered to indicate that the difference was statistically significant.

\section{Results}

Treg and Th17 cell contents in the peripheral blood of children in the two groups. The flow cytometry results for the quantification of Treg and Th17 cells in the peripheral blood of the subjects are presented in Figs. 1-3. Compared with that in the normal control group, the Treg cell ratio in the peripheral blood of children with acute bronchitis was significantly decreased and the Th17 cell ratio was significantly increased $(\mathrm{P}<0.05)$. Compared with that in the control group, the Treg/Th17 ratio in the peripheral blood of children with acute bronchitis was significantly decreased $(\mathrm{P}<0.05)$.

Serum cytokine levels in the two groups. Various serum cytokines in the two groups were assessed by ELISA (Fig. 4). Compared with those in the normal control group, the levels 
A

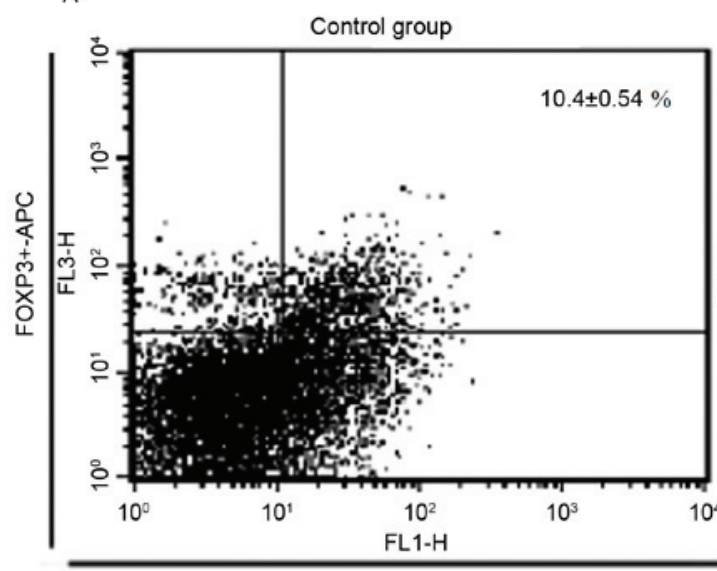

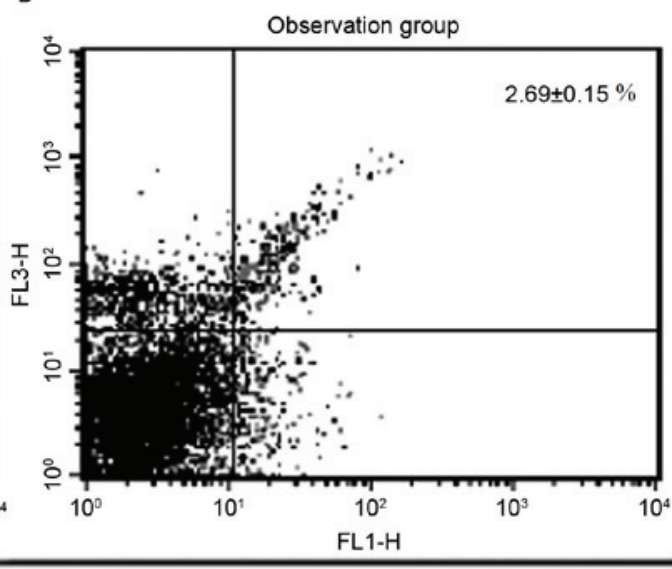

CD4-FITC

Figure 1. Representative flow cytometry dot plot of T-regulatory cells of children in (A) the control and (B) the observation group. FOXP3, forkhead box P3; APC, allophycocyanin; FITC, fluorescein isothiocyanate.

A

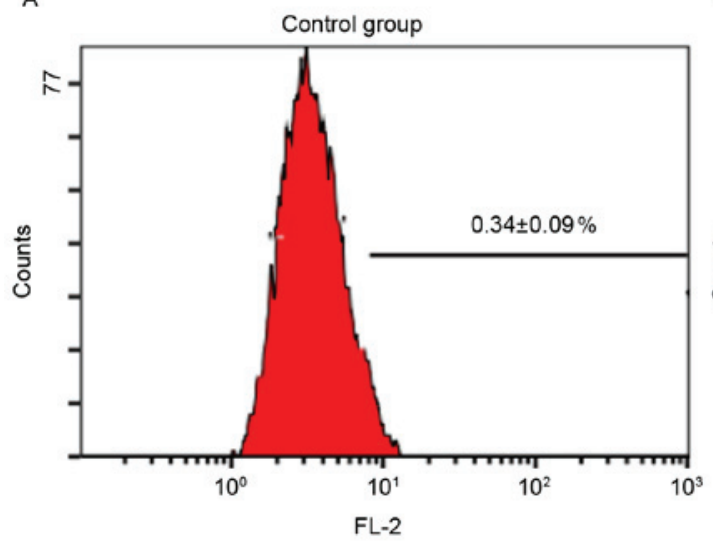

B

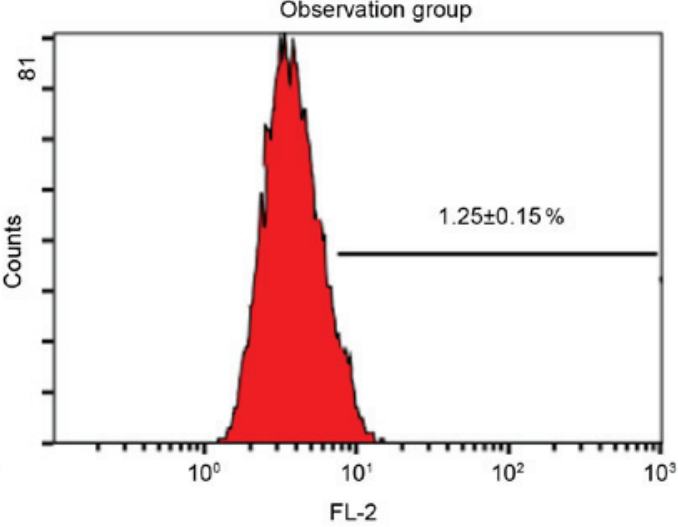

Figure 2. Representative flow cytometry histograms for the analysis of type 17 T-helper cells of children in the two groups. The isotype sample was used as a control.

of serum IL-17 and IL-22 in children with acute bronchitis were significantly increased $(\mathrm{P}<0.05)$. The levels of IL-10 and TGF- $\beta$ were significantly decreased $(\mathrm{P}<0.05)$.

\section{Discussion}

Acute bronchitis is bronchial mucosa caused by a virus, bacterium and other pathogenic infection. It is one of the most common types of respiratory disease. It is usually accompanied with elevated body temperature above $38^{\circ} \mathrm{C}$, cough and other clinical manifestations. At the molecular level, the physiopathological basis of the disease may be summarized as an airway inflammation caused by the imbalance between pro-inflammatory cytokines and anti-inflammatory factors $(14,15)$. The inflammatory reaction is associated with an imbalance of Th cell (CD4 ${ }^{+} \mathrm{T}$ cell) subpopulations, which include Th1, Th2, Th17 and Treg cells. Th cells have a regulatory role in inducing the inflammatory response or suppressing immune responses $(16,17)$.

A previous study suggested that an imbalance in the inflammatory cytokine network caused by a Th1/Th2 imbalance had an important role in the occurrence and development of numerous diseases (18). After Treg and Th17 cells had been successively identified, the imbalance between Treg and Th17 cells as well as their cytokines became the theoretical basis of various autoimmune disorders and other diseases. Th17 and Treg cells are an important supplement to the theory of the immune balance function of Th1 and Th2. Th1/Th2 imbalance is closely associated with various autoimmune diseases (19-21). Th17 has an important role in the defense against extracellular bacterial infection and mediation of autoimmune diseases, which has an important role mainly through the secretion of IL-22, IL-17 and other cytokines. Among them, IL-17 is the most important effector molecule. It mediates the local infiltration of inflammatory cells through inducing the expression of IL-22 and other inflammatory cytokines, so as to cause tissue damage. Treg cells have a negative regulatory role in the body's immune system. They not only inhibit inappropriate immune responses, but also limit the scope, extent and duration of an immune response. Treg cells exert their regulatory role mainly through IL-10 and TGF- $\beta(22,23)$. Studies have confirmed that Th17/Treg imbalance widely exists in autoimmune and infectious diseases, with an increased rate of Th17 cells, 
A

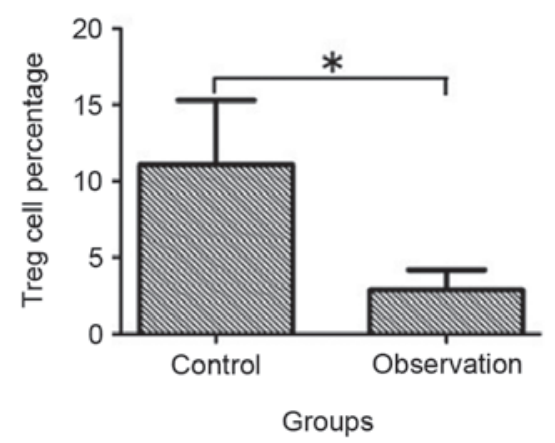

B

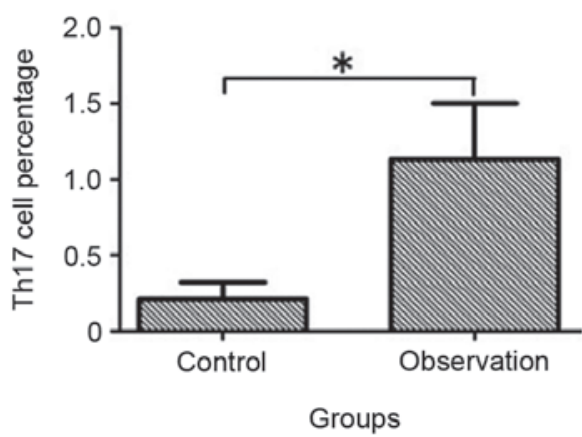

C

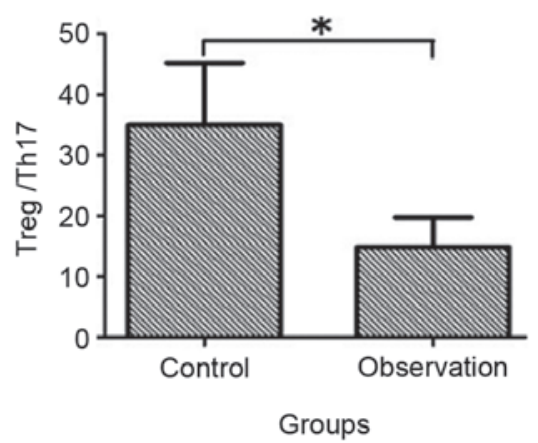

Figure 3. Comparison of Treg vs. Th17 ratio in children of the two groups. (A) Treg percentage; (B) Th17 percentage; (C) Treg/Th17 ratio. "P<0.05. Treg, T-regulatory cell; Th17, type 17 T-helper cell.

A

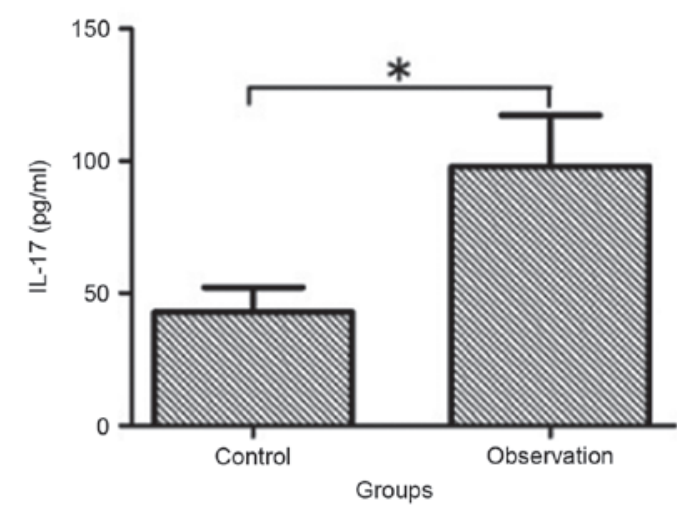

C

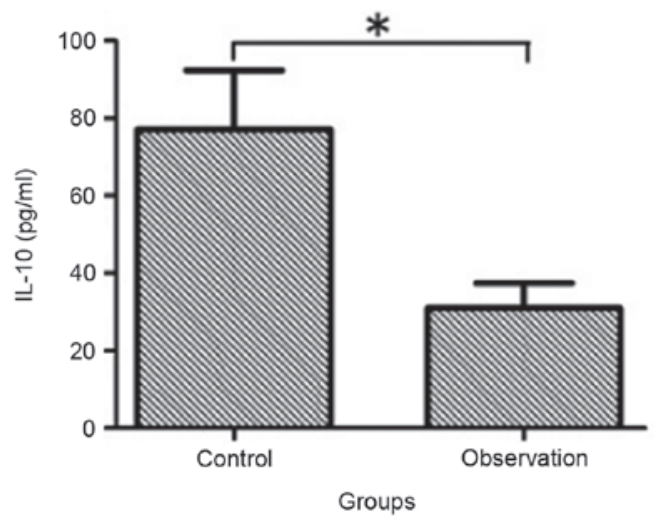

B

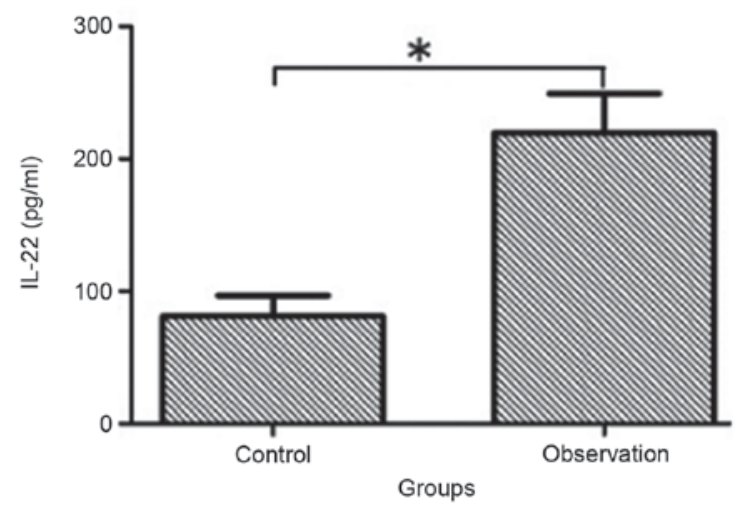

D

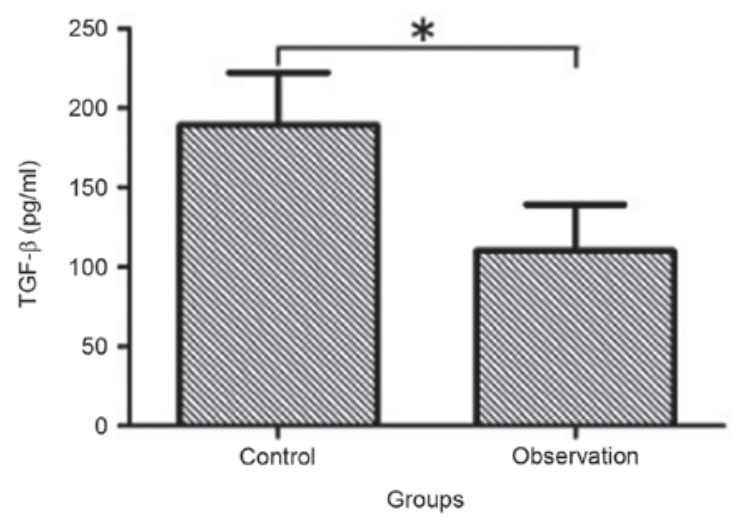

Figure 4. Comparison of the serum levels of (A) IL-17, (B) IL-22, (C) IL-10 and (D) TGF- $\beta$ in children of the two groups. *P<0.05. TGF, transforming growth factor; IL, interleukin.

while $\mathrm{CD} 4{ }^{+} \mathrm{CD} 25^{+}$Treg cells are decreasing. The Th17/Treg imbalance is more obvious, accompanied by the aggravation of the disease (24).

The present study aimed to investigate the role of Treg and Th17 cells in the pathogenesis of acute bronchitis by detecting the levels of Treg and Th17 cells as well as their associated cytokines in the peripheral blood of children with acute bronchitis. The results demonstrated that compared with healthy children, the Treg cell rate, the Treg/Th17 ratio, and the serum levels of IL-10 and TGF- $\beta$ in the peripheral blood of children with acute bronchitis were significantly decreased $(\mathrm{P}<0.05)$, while the Th17 cell rate as well as IL-17 and IL-22 levels were significantly increased $(\mathrm{P}<0.05)$. The above results suggested that imbalance of the Th17/Treg ratio has an important role in the occurrence and development of acute bronchitis, which may provide a basis for further study of the pathogenesis of acute bronchitis as well as guidance for clinical treatment. 


\section{References}

1. Park MJ, Rhee CK, Kim YH, Kim DJ, Kim DG, Lee SY and Kim JY: Efficacy and safety of HL301 in the treatment of acute bronchitis and acute exacerbation of chronic bronchitis: A phase 2, randomized, double-blind, placebo-controlled, multicenter study. Curr Med Res Opin 33: 919-925, 2017.

2. Hart AM: Evidence-based diagnosis and management of acute bronchitis. Nurse Pract 39: 32-40, 2014.

3. Ncube NB, Solanki GC, Kredo T and Lalloo R: Antibiotic prescription patterns of South African general medical practitioners for treatment of acute bronchitis. S Afr Med J 107: 119-122, 2017.

4. Wang P, Liao X, Xie YM, Chai Y and Li LH: Tanreqing injection for acute bronchitis disease: A systematic review and meta-analysis of randomized controlled trials. Complement Ther Med 25 143-158, 2016.

5. Aguilar PR, Balsara K, Itoh A and Kollef MH: A noteworthy case of acute bronchitis. Ann Am Thorac Soc 13: 285-287, 2016.

6. Park S, Oh KC, Kim KS, Song KT, Yoo KH, Shim YS, Lee YJ, Lee MG, Yun JU, Kim HS, et al: Role of atypical pathogens and the antibiotic prescription pattern in acute bronchitis: A multicenter study in Korea. J Korean Med Sci 30: 1446-1452, 2015.

7. Magin PJ, Morgan S, Tapley A, Henderson KM, Holliday EG, Ball J, Davis JS, Dallas A, Davey AR, Spike NA, et al: Changes in early-career family physicians' antibiotic prescribing for upper respiratory tract infection and acute bronchitis: A multicentre longitudinal study. Fam Pract 33: 360-367, 2016.

8. Gehrke-Beck S and Holzinger F: Less is more-cough and acute upper respiratory tract infections. MMW Fortschr Med 159: 44-51, 2017.

9. Fal AM and Schönknecht K: Efficacy and safety of acute bronchitis treatment in adults-a comparison of Bronchosol ${ }^{\circledR}$ syrup and synthetic preparations with ambroxol. Results of observational study. Wiad Lek 68: 139-144, 2015.

10. Black JT: Capsule commentary on michaelidis et al., Cost-Effectiveness of decision support strategies in acute bronchitis. J Gen Intern Med 31: 328, 2016.

11. Asarat M, Apostolopoulos V, Vasiljevic T and Donkor O: Short-Chain fatty acids regulate cytokines and Th17/Treg cells in human peripheral blood mononuclear cells in vitro. Immunol Invest 45: 205-222, 2016.

12. Lim SM, Kang GD, Jeong JJ, Choi HS and Kim DH: Neomangiferin modulates the Th17/Treg balance and ameliorates colitis in mice. Phytomedicine 23: 131-140, 2016.
13. Zhu FT: Practical Paediatrics. 7th edition. People's Medical Publishing House, Beijing, pp1132, 2005.

14. Michaelidis CI, Kern MS and Smith KJ: Cost-Effectiveness of decision support strategies in acute bronchitis. J Gen Intern Med 30: 1505-1510, 2015.

15. Singh $M$ and Koyfman A: Are antibiotics effective in the treatment of acute bronchitis? Ann Emerg Med 65: 566-567, 2015.

16. Smiyan OI, Plakhuta VA, Bunda TP and Popov SV: Dynamics of cytokines in infants with acute obstructive bronchitis and thymomegalia. Lik Sprava: 81-85, 2015.

17. Ghosh R, Rossner P, Honkova K, Dostal M, Sram RJ and Hertz-Picciotto I: Air pollution and childhood bronchitis: Interaction with xenobiotic, immune regulatory and DNA repair genes. Environ Int 87: 94-100, 2016.

18. Talaat RM, Mohamed SF, Bassyouni IH and Raouf AA: Th1/Th2/Th17/Treg cytokine imbalance in systemic lupus erythematosus (SLE) patients: Correlation with disease activity. Cytokine 72: 146-153, 2015.

19. Tahan F, Celik S and Eke Gungor H: Effect of montelukast on clinical score and cytokine levels of infants for clinically diagnosed acute bronchiolitis. Allergol Immunopathol (Madr) 43: 376-382, 2015.

20. Wan CF, Zheng LL, Liu Y and Yu X: Houttuynia cordata Thunb reverses oxaliplatin-induced neuropathic pain in rat by regulating Th17/Treg balance. Am J Transl Res 8: 1609-1614, 2016.

21. Cheng H, Xi Y, Chi X, Wu Y and Liu G: Fenofibrate treatment of rats with experimental autoimmune myocarditis by alleviating Treg/Th17 disorder. Cent Eur J Immunol 41: 64-70, 2016.

22. Yang L, Sun SY, Xue Q, Li B, Tian HW, Liu XJ, Yan HM and Dai EH: Alterations of Treg cells, Th17 cells and some related cytokines in peripheral blood of patients with hand-foot-mouth disease. Chin J Microbiol Immunol 34: 697-703, 2014.

23. Handono K, Pratama MZ, Endharti AT and Kalim H: Treatment of low doses curcumin could modulate Th17/Treg balance specifically on $\mathrm{CD} 4^{+} \mathrm{T}$ cell cultures of systemic lupus erythematosus patients. Cent Eur J Immunol 40: 461-469, 2015.

24. Kang GD, Lim S and Kim DH: Oleanolic acid ameliorates dextran sodium sulfate-induced colitis in mice by restoring the balance of Th17/Treg cells and inhibiting NF- $\kappa \mathrm{B}$ signaling pathway. Int Immunopharmacol 29: 393-400, 2015. 